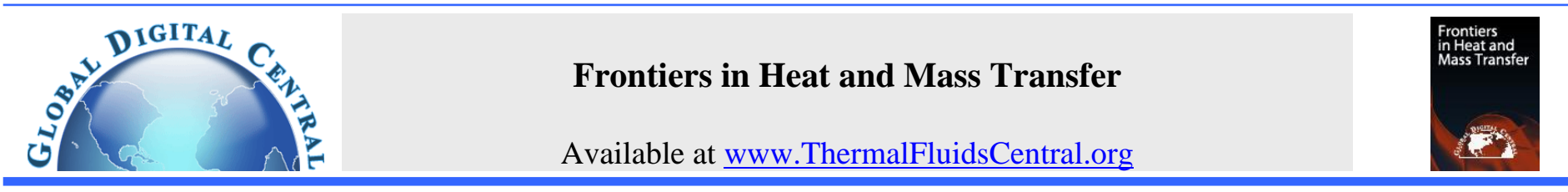

\title{
FLUID FLOW AND HEAT TRANSFER OVER A STRETCHING SHEET WITH TEMPERATURE DEPENDENT PRANDTL NUMBER AND VISCOSITY
}

\author{
N. Govindaraj, A. K. Singh, Pankaj Shukla \\ Mathematics Division, School of Advanced Science, VIT Chennai, Chennai - 600127, India
}

\begin{abstract}
A numerical study of fluid flow over stretching sheet with temperature dependent properties has been performed induced by mixed convection. The significant variation of the Prandtl number and viscosity in the temperature is observed [see table 1]. Viscosity and Prandtl number are vary in inverse of the linear function. The physical problem modeled in the mathematical equations in dimension form, which is converted to the non-dimensional equations by applying similarity transformations and suitable boundary conditions. The mathematical modelling problem is transformed PDE's are numerically solved using Quasilinearization technique and FDM. The current numerical data has been presented in terms of velocity and heat transfer profiles and including the appropriate physical reason. The graphically represented the temperature and velocity distribution has been analyzed in detail. It has been found that the temperature and velocity profiles increases with decrease of $m$. The various parameter values of buoyancy force, Ratio between free stream velocity and the reference velocity and stream function are increases with higher value $m=1$ acting in near to the plate on the velocity profile but temperature profile acting on away from the plate. The skin friction and heat transfer fluid flow enhance the buoyancy force. In particular 82 percentage and 2 percentage increment in skin friction and heat transfer is observed that buoyancy force increases from 2 to 3 at other parameters are fixed. The stretching sheet fluid flow behaviors enrich the solution and understand the boundary layers.
\end{abstract}

Keywords: Power law Stretching Sheet, Mixed Convection, Water Boundary Layer, Variable Physical Parameters, Quasilinearization Technique.

\section{INTRODUCTION}

In this study, the heat transfer through fluid flow moving over a stretching surface with various physical parameter due to its significant application in engineering and industry fields. such as wire drawing, continuous casting of fibers and paper production, fabricate of plastic/rubber sheets, aerodynamic extrusion of plastic sheets, cooling of metallic plate, glass blowing. Recently, the fluid flow over stretching sheet has been got special attention because of many practical applications in industry as different characteristics of final product depending the cooling in the processes and stretching surface. In order to understand the phenomenon of stretching surface, Crane (1970) first time presented the mixed convection flow over stretching surface.

Later, various authors have been investigated many problems using Boundary layer theory. Patil et al., (2010) discussed the momentum and thermal profiles using power law in form of the skin friction, composite velocity and buoyancy force. Makinde et al., (2013) analyzed the mixed convection nanofluid flow moving over stretching sheet. It is found that nusselt number decreases with increase of buoyancy force. Afzal (2003) examined laminar fluid flow over stretching surface using power law with measure the ratio of free stream velocity and stretching sheet velocity. Nadeem et al., (2014) studied the linear stretching MHD flow in two lateral direction.

Sravanthi (2019) analyzed the heat transfer flow due to the rotat- ing disk with variable thickness and using the homotopy method. They found that the nonlinear radiation small effect of the temperature. Sravanthi (2009) discussed the MHD fluid flow due to porous rotating disk with variable thickness is high impact of the fluid velocity, temperature, and concentration. Sravanthi (2019) examined the nonlinear thermal radiation of the nanofluid flow over cone with heat source and sink. The nonlinear thermal radiation increases as compare to the linear thermal radiation. The porous media of MHD flow of ciliary propulsion of microscopic organism. They found $\mathrm{t} 2$ hat the Hartmann number, Hall and ion slip parameters on the velocity field has been presented by Krishnaa et al., (2020). Sravanthi (2018) studied the nanofluid flow moving over a stretching vertical cylinder. The heat transfer decreases with increase of both space and heat source/sink parameter. Sravanthi and Gorla (2018) analyzed the MHD maxwell nanofluid moving over exponential stretching sheet with chemical reaction of the various set of parameters. Sravanthi and Gorla (2018) discussed the chemical reaction of the rivlin ericksen flow moving over porous plate. The temperature and velocity are controlled by thermal absorption. Sheikholeslami et al., (2020) examined the acceleration discharge process of clean energy with nanofluid enhance the paraffin. Heat transfer to air reduces with increase of lower temperature of outer air. Rezaeianjouybari et al., (2020) presented the bayesian flow condensation enhancement using nanorefrigerant. The nanoparticle concentration increases with decrease of heat flux. Sheikholeslami

*Corresponding author. Email: abhishek.iitm1@gmail.com 
(2019) examined the porous media of the nanofluid flow of impact of lorentz force. The energy drop detracts with reduce of magnetic force. Sheikholeslami et al., (2019) studied the nano refrigerant for boiling heat transfer flow increased the nanoparticle concentration term.

A detail study of the three dimensional nanofluid flow over an exponentially stretching sheet has been done by Nadeem et al., (2014). Chen (2000) presented the heat transfer fluid flow upon moving stretching sheet and they found that the nusselt number, skin friction coefficient and buoyancy force for VWT and VHF. Ismail et al., (2016) analyzed the two dimensional fluid flow upon flat plate moving in similar direction to the free stream with constant heat flux. Mureithi et al., (2013) examined the boundary layer fluid flow over moving heated surface with temperature dependent viscosity and streaming flow velocity. The viscosity variation parameter plays a vital role on the velocity and temperature distribution.

Kandasamy et al., (2018) studied the mixed convection nanofluid fluid flow over a porous plate and included the thermal and solutal stratification. The temperature and concentration decreases with increase thermal and solutal stratification. Alreshidi et al., (2020) presented the MHD flow due to the rotating disc for heat and mass transformation and viscous dissipation. Shah et al., (2020) examined nanofluid flow moving over a stationary channel with thermal radiation. Revathi et al., (2014) studied the fluid flow over yawed cylinder and effect of yaw angle. The yaw angle increased with skin friction and heat transfer decreased. Elbashbeshy (2001) numerically analyzed the quiescent fluid moving over exponentially stretching sheet. The variation of heat transfer rate is proportional to Prandtl number whereas inversely proportional of suction parameter. Hayat et al., (2014) investigated three dimensional fluid flow over exponential stretching sheet. They presented the effects of various parameters on temperature and volume friction with impact of three different types of chemical reactions. Mabood and Shateyi (2019) analyzed the unsteady fluid flow with thermal and MHD effects. Govindaraj et al., (2019) discussed the heat transfer and skin friction coefficient fluid flow over an exponentially stretching sheet. Umavathi et al., (2016) examined convection flow moving over a vertical channel with viscous dissipation. It is found that the viscosity and thermal conductivity have shown significant effects on buoyancy ratio and temperature ratio and hence on the velocity and temperature field.

Dulal (2017) studied the MHD fluid flow moving over exponentially stretching sheet. The local Nusselt number increases as increase in Prandtl number and strength of the magnetic field. Raju et al., (2016) discussed the MHD and chemical reaction's parameters reduce the skin friction. Casson fluid is high impact in heat transfer compare to the Newtonian fluid. Uddin et al., (2015) analyzed double diffusive convective flow over plate. They found that the buoyancy force reduces the concentration and temperature profile, while increase the velocity profile. The heat transfer increases in thermal and momentum with decrease in concentration profile. Ibseini and Makinde (2013) examined chemical reaction of the MHD fluid flow over a stretching surface. The MHD flow significant effects of velocity and temperature distribution. The heat transfer decreases with increase of MHD. The future scope of the current work are follows as:

1. Study of mixed convection nano fluid flow over a exponential stretching sheet with different Prandtl number and different viscosity.

2. Study of steady/unsteady MHD fluid flow over linear/exponentially stretching sheet under the influence of heat generation with variable Prandtl number and viscosity.

3. Study of chemical reaction of the nano fluid over exponentially stretching sheet with thermal radiation and variable viscosity and variable Prandtl Number.

The current investigation has been done on mixed convection fluid flow over a stretching surface with variable viscosity and variable Prandtl number. The stretching sheet plays an important role in heat transfer which occur many engineering processes such as rubber sheet, polymer process and plastic. The base fluid has been consider as water which is working in many engineering applications. The numerical solutions of the nonlinear PDE's have been obtained using QLT with FDM. The current results are validated to the previous existing results by Chen, (1998); Tsou et al., (1967); Soundalgekar and Murty, (1980) and its found good agreement.

\section{MATHEMATICAL MODELLING}

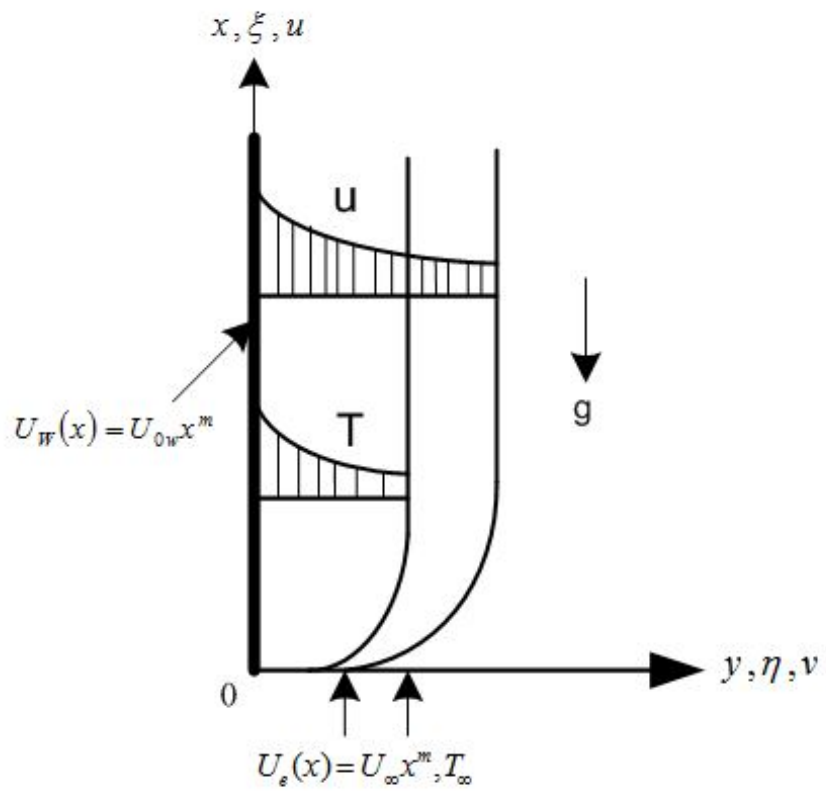

Fig. 1 Physical model and coordinate system

We consider the fluid flow over moving stretching sheet with temperature dependent physical parameters of fluid. The cartesian coordinate (x-y plane) have been selected with vertically upward in the $\mathrm{x}$-axis and its normal as $\mathrm{y}$-axis (see Figure 1). The exponent parameters (m) play an essential role in velocity and thermal fluid flow distribution over moving stretching sheet. Figure 1 shows that the physical model flow with the coordinate system. The buoyancy force rise on the temperature difference in the fluid fl ow. Assume that the fluid flow varies on moderate velocities, the temperature difference between free streams and wall is less then $\left(<50^{\circ} \mathrm{C}\right)$. In the range of temperature $\left(0-50^{\circ} \mathrm{C}\right)$, the variation of both specific heat $\left(C_{p}\right)$ and density $(\rho)$ of w ater temperature is less than $1 \%$ and hence it is considered the constant values. Since viscosity $(\mu)$, prandtl number $(P r)$ and thermal conductivity $(\mathrm{k})$ with temperature are quite significant, thus temperature dependent $v$ iscosity a nd Prandtl number are vary in inverse of linear function of temperature $(T)$. (Roy and Saikrishna, (2003); Schlichting, (2000); Pop et al., (1992)).

Table 1: Values of thermophysical properties of water at different temperature by Lide (1990).

\begin{tabular}{|c|c|c|c|c|c|}
\hline $\begin{array}{c}\text { Temperature } \\
(\mathrm{T})\left({ }^{\circ} \mathrm{C}\right)\end{array}$ & $\begin{array}{c}\text { Density } \\
\left(\mathrm{g} / \mathrm{cm}^{3}\right)\end{array}$ & $\begin{array}{c}\text { Specific heat } \\
\left(\mathrm{J} .10^{7} / \mathrm{kg} \mathrm{K}\right)\end{array}$ & $\begin{array}{c}\text { Thermal conducti- } \\
\left.\text { vity(erg. } 10^{5} / \mathrm{cm} . \mathrm{s} . \mathrm{K}\right)\end{array}$ & $\begin{array}{c}\text { Viscosity }\left(\mathrm{g} .10^{-2}-\right. \\
/ \mathrm{cm} . \mathrm{s})\end{array}$ & $\begin{array}{c}\text { Prandtl } \\
\text { No } P r\end{array}$ \\
\hline 0 & 1.00228 & 4.2176 & 0.5610 & 1.7930 & 13.48 \\
\hline 10 & 0.99970 & 4.1921 & 0.5800 & 1.3070 & 9.45 \\
\hline 20 & 0.99821 & 4.1818 & 0.5984 & 1.0060 & 7.03 \\
\hline 30 & 0.99565 & 4.1784 & 0.6154 & 0.7977 & 5.12 \\
\hline 40 & 0.99222 & 4.1785 & 0.6305 & 0.6532 & 4.32 \\
\hline 50 & 0.98803 & 4.1806 & 0.6435 & 0.5470 & 3.55 \\
\hline
\end{tabular}

$$
\mu=\frac{1}{b_{1}+b_{2} T} \quad N=\frac{\mu}{\mu_{\infty}}=\frac{b_{1}+b_{2} T_{\infty}}{b_{1}+b_{2} T}=\frac{1}{1+a_{1} \theta}
$$




$$
\begin{aligned}
& a_{1}=\frac{b_{2}\left(T_{\infty}-T_{w}\right)}{b_{1}+b_{2} T_{\infty}}, \operatorname{Pr}=\frac{1}{c_{1}+c_{2} T}=\frac{1}{a_{2}+a_{3} \theta} \\
& a_{3}=c_{2}\left(T_{\infty}-T_{w}\right), a_{2}=c_{1}+c_{w}, \Delta T_{w}=\left(T_{\infty}-T_{w}\right)
\end{aligned}
$$

Here $c_{1}=0.068, \quad c_{2}=0.004, b_{1}=53.41, \quad b_{2}=2.43$.

The above assumptions, the governing equations as follows as Singh and Roy (2008), Schlichting (2000), Roy and Saikrishna(2003), Pop et al.(1992):

$$
\begin{gathered}
\frac{\partial u}{\partial x}+\frac{\partial v}{\partial y}=0 \\
u \frac{\partial u}{\partial x}+v \frac{\partial u}{\partial y}=U_{e}\left(\frac{d U_{e}}{d x}\right)+\frac{1}{\rho} \frac{\partial}{\partial y}\left(\mu \frac{\partial u}{\partial y}\right)+g\left[\beta\left(T-T_{\infty}\right)\right] \\
u \frac{\partial T}{\partial x}+v \frac{\partial T}{\partial y}=\frac{1}{\rho} \frac{\partial}{\partial y}\left(\frac{\mu}{\operatorname{Pr}} \frac{\partial T}{\partial y}\right)
\end{gathered}
$$

along with the relevant boundary conditions

$$
\begin{array}{r}
\text { At the plate, } y=0: \quad u(x, 0)=U_{W}(x), \quad v=0, T=T_{W} \\
\text { Away from the plate, } y \rightarrow \infty: \quad u \rightarrow U_{e}(x), T \rightarrow T_{\infty}
\end{array}
$$

Applying the similarity transformations

$$
\begin{gathered}
\psi(x, y)=\left(U x^{m+1} \nu\right)^{1 / 2} f(\xi, \eta) ; \quad \xi=\frac{x}{L} ; \eta=\left(\frac{U x^{m}}{x \nu}\right)^{1 / 2} y ; \\
v=\frac{\partial \psi}{\partial x} ; u=\frac{\partial \psi}{\partial y} ; \quad G r=\frac{g \beta_{T}\left(T_{w}-T_{\infty}\right) L^{3}}{\nu^{2}} ; \lambda=\frac{G r}{R e_{L}^{2}} ; \\
v=-\frac{(U \nu)^{1 / 2} x^{\frac{m-1}{2}}}{2}\left\{(m-1) \eta F+(m+1) f+2 \xi f_{\xi}\right\} ; \\
\lambda=\frac{G r}{R e_{L}^{2}} ; T-T_{\infty}=\left(T_{w}-T_{\infty}\right) \theta(\xi, \eta) ; u=U x^{m} f_{\eta} ; \\
\operatorname{Re}_{L}=\frac{U x^{m} L}{\nu} ; U_{W}(x)=U_{0 w} x^{m} ; U_{e}(x)=U_{\infty} x^{m}
\end{gathered}
$$

The Equation (1) it is true for identically, we obtain a system of nonlinear equations (2) and (3) with boundary constraints

$$
\begin{gathered}
\left.\left(N F_{\eta}\right)_{\eta}+\left(\frac{m+1}{2}\right) f F_{\eta}+m\left(\epsilon^{2}-F^{2}\right)+\lambda \xi \theta-\xi F F_{\xi}-\xi f_{\xi} F_{\eta}\right)=0 \\
\left(N \operatorname{Pr}^{-1} \theta_{\eta}\right)_{\eta}+\left(\frac{m+1}{2}\right) f \theta_{\eta}-\xi F \theta_{\xi}-\xi \theta_{\eta} f_{\xi}=0
\end{gathered}
$$

The nondimensional boundary constraints

$$
\begin{array}{r}
\theta=1, \quad F=-\varepsilon+1 \text { at } \eta=0 \\
\theta=0, \quad F=\varepsilon \text { at } \eta=\eta_{\infty}
\end{array}
$$

Here $\mathrm{N}$ represents a viscosity ratio, The positive sign indicate $(N>0)$ both thermal and buoyancy force acting on same direction while the negative sign indicates $(N<0)$ acting on opposite direction. In Eq. (6) the buoyancy parameter $(\lambda)$ represents the effect of the flow field, whose sign arise \pm . The $\lambda=0$ indicated the no buoyancy force. The buoyancy force positive sign indicates flow moving the same direction, negative sign indicate flow moving opposite direction.

Further,

$$
f=\int_{0}^{\eta} F d \eta+f_{w} ; f_{w}=0
$$

Here, $f_{w}=0$ impermeable plate. $U=U_{\infty}+U_{0 w}$ is the composite velocity, $\varepsilon=\frac{U_{\infty}}{U_{\infty}+U_{0 w} w}$ is the ratio velocity.

The skin friction $\left(C_{f x}\right)$ is defined by

$$
\begin{array}{r}
C_{f x}=\mu \frac{2\left(\frac{\partial u}{\partial y}\right)_{y=0}}{\rho U^{2}}=2 F_{\eta}(\xi, 0)\left(R e_{L} \xi\right)^{-1 / 2} \\
\text { i.e, } C_{f x}\left(R e_{L} \xi\right)^{1 / 2}=2 F_{\eta}(\xi, 0)
\end{array}
$$

Nusselt number $\left(N u_{x}\right)$ is defined by

$$
\begin{array}{r}
N u_{x}=-x \\
\frac{\left(\frac{\partial T}{\partial y}\right)_{y=0}}{\left(T_{w}-T_{\infty}\right)}=\theta_{\eta}(\xi, 0)\left(R e_{L} \xi\right)^{1 / 2} \\
i . e, N u_{x}\left(R e_{L} \xi\right)^{-1 / 2}=-\theta_{\eta}(\xi, 0)
\end{array}
$$

\section{NUMERICAL COMPUTATION}

The dimensionless set of coupled nonlinear PDE's (6) and (7) with boundary condition (8) is obtained numerical data using an FDM in combination with the Quasi-linearization technique. The PDE's are obtained by applying Quasi-linearization technique on Eqns. (6)-(7) which are follows as

$$
\begin{gathered}
X_{1}^{p} F_{\eta \eta}^{p+1}+X_{2}^{p} F_{\eta}^{p+1}+X_{3}^{p} F^{p+1}+X_{4}^{p} F_{\xi}^{p+1}+X_{5}^{p} \theta_{\eta}^{p+1}+X_{6}^{p} \theta^{p+1}=X_{7}^{p} \\
Y_{1}^{p} \theta_{\eta \eta}^{p+1}+Y_{2}^{p} \theta_{\eta}^{p+1}+Y_{3}^{p} \theta^{p+1}+Y_{4}^{p} \theta_{\xi}^{p+1}+Y_{5}^{p} F^{p+1}=Y_{6}^{p}
\end{gathered}
$$

The unknown function of the index term $(p+1)$ are determined by using the know function of index term $(p)$. The boundary constraints for Eqns. (11)-(12) are followed as

$$
\begin{array}{r}
\theta^{p+1}=1, F^{p+1}=-\varepsilon+1, \text { at } \eta=0 \\
\theta^{p+1}=0, F^{p+1}=\epsilon, \text { at } \eta=\eta_{\infty}
\end{array}
$$

The variable coefficients, correspond to Eqs.(11-12) are listed here.

$X_{1}^{p}=N$

$X_{2}^{p}=-a_{1} N^{2} \theta_{\eta}+(m+1) \frac{f}{2}+\xi f_{\xi}$

$X_{3}^{p}=-\xi F_{\xi}-2 m F$

$X_{4}^{p}=-\xi F$

$X_{5}^{p}=-a_{1} N^{2} F_{\eta}$

$X_{6}^{p}=-a_{1} N^{2} F_{\eta \eta}+2 a_{1}^{2} N^{3} F_{\eta} \theta_{\eta}+\lambda \xi$

$X_{7}^{p}=-2 a_{1} N^{2} F_{\eta} \theta_{\eta}+2 a_{1}^{2} N^{3} F_{\eta} \theta_{\eta} \theta-\xi F F_{\xi}-m\left(F^{2}+\epsilon^{2}\right)$

$Y_{1}^{p}=N p r^{-1}$

$Y_{2}^{p}=-2 a_{1} N^{2} p r^{-1} \theta_{\eta}+2 a_{3} \theta_{\eta} N+(m+1) \frac{f}{2}+\xi f_{\xi}$

$Y_{3}^{p}=a_{3} N \theta_{\eta \eta}-a_{1} N^{2} p r^{-1} \theta_{\eta \eta}-2 a_{1} a_{3} N^{2} \theta_{\eta}^{2}+2 a_{1}^{2} N^{3} p r^{-1} \theta_{\eta}^{2}$

$Y_{4}^{p}=-\xi F$

$Y_{5}^{p}=-\xi \theta_{\xi}$

$Y_{6}^{p}=a_{3} \theta_{\eta}^{2} N-a_{1} \theta_{\eta}^{2} p r^{-1} N^{2}+a_{3} \theta_{\eta \eta} \theta N-a_{1} \theta_{\eta \eta} \theta p r^{-1} N^{2}-2 a_{1} a_{3} \theta_{\eta}^{2} \theta N^{2}$ $+2 p r^{-1} a_{1}^{2} \theta_{\eta}^{2} \theta N^{3}-\xi F \theta_{\xi}$

The current problem consists of nonlinear PDEs which is solved by applying the Quasillinearization technique along with FDM. Quasilinearization technique is widely used to solve different types of nonlinear ordinary partial differential equations. In this method, an iterative sequence of linear equations is carefully constructed to approximate the nonlinear equations. Thus in, each iteration step is reduce to a system of linear equations, which is solved by Varga's algorithm (2000). The system of linear PDE eqs. (11)-(12) are expressed by $\eta$ and $\xi$-directions. The step size $\Delta \eta$ and $\Delta \xi$ has been chosen as 0.01 and 0.02 , respectively. The efficiency and accuracy of the method have been illustrated through it is applications to many boundary value problems. The step size is presented in four decimal places. The convergence criterion based on the difference between the current and previous iteration values is employed. The Quasilinearization technique has quadratic convergence and monotonicity. 


\section{RESULTS AND DISCUSSION}

In our present study the numerical values of the dimensional parameters have been graphically presented in terms of $F, \theta, C_{f x}$ and $N u_{x}$ for different values of $\varepsilon(0.1 \leq \varepsilon \leq 0.5), \lambda(-1 \leq \lambda \leq 2)$, and $\xi(0 \leq \xi \leq 1)$. Comparisons of the present numerical value of the heat transfer coefficient are found to be in good agreement with previous available results (see Table 2).

Table 2: Validation of current work with previous works for $-\theta_{\eta}(0)$ at $\xi=0, \lambda=0, \epsilon=0$.

\begin{tabular}{|c|c|c|c|c|}
\hline$P r$ & 2 & 7 & 10 & 100 \\
\hline Chen (1998) & 0.6832 & 1.3869 & 1.6800 & 5.5445 \\
\hline Tsou et al. (1980) & - & - & 1.6804 & 5.545 \\
\hline Soundal. and Murty (1967) & 0.6831 & - & 1.6808 & - \\
\hline Present work & 0.6830 & 1.3880 & 1.6803 & 5.5452 \\
\hline
\end{tabular}

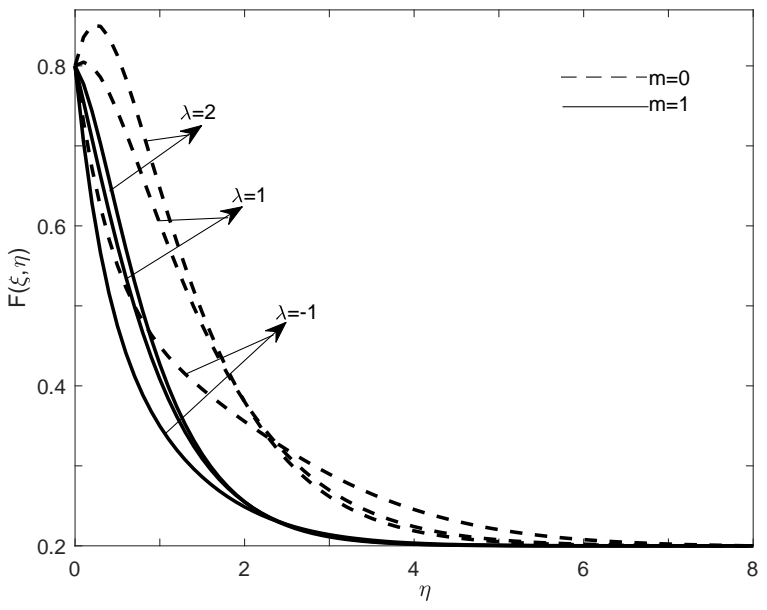

Fig. 2 Effects of $\lambda$ and $m$ on velocity profile for $\epsilon=0.2$ and $\xi=1.0$

Figure 2 exhibits the effect of $\lambda$ and $m$ on the velocity profiles $(F)$. The velocity profile increases with increase of $\lambda$, while decreases with increase of $m$ for $\xi=1.0$ at $\epsilon=0.2$. Significant variation in velocity profile is observed with $\lambda$ for $m=0$ as compared to $m=1$. It is noted that the variation in velocity profile is more significant for $m=0$ as compared to $m=1$ with the change of buoyancy force $(\lambda)$. The velocity is high for $\lambda>0$ due to enhance buoyancy force as compare to $\lambda<0$. Further, slight overshoot in the velocity profile is observed for $m=0$ and $\lambda=2$ where as overshoot not noticed for $m=1$, irrespective of $\lambda$. In particular, for $\epsilon=0.2, \lambda=2$ and $m=0$, the velocity profile overshoot increases close by $6 \%$ as $\eta$ increases from $\eta=0$ to 0.2 at $\xi=1.0$. The decreasing nature in $\mathrm{F}$ is noticed for lower values of $\eta(0 \leq \eta \leq 2)$ for all values of $m$ and $\lambda$. On the other hand $F$ nearly maintain constant values for range of $\eta(6 \leq \eta \leq 8)$ irrespective of $m$ and $\lambda$. The physical reason is that the velocity profile within boundary layer as the assisting buoyancy force acts like a favorable pressure gradient which enhance the velocity profile. For example, when $\epsilon=0.2, \xi=1.0$ and $\eta=1$, the $F$ decreases approximately about $29 \%$ by increment in $m$ from 0 to 1 at $\lambda=1$. The impacts of the exponent parameter and buoyancy parameter on temperature variation are presented in Figure 3. It may be noted that the thermal boundary layer thickness $(\theta)$ decreases with increase of $m$ but increases with decrease of $\lambda$. The heat transfer enhances thermal diffusion with decreases of $m$ and buoyancy force slows down the rate of thermal diffusion within the boundary layer. The buoyancy and the

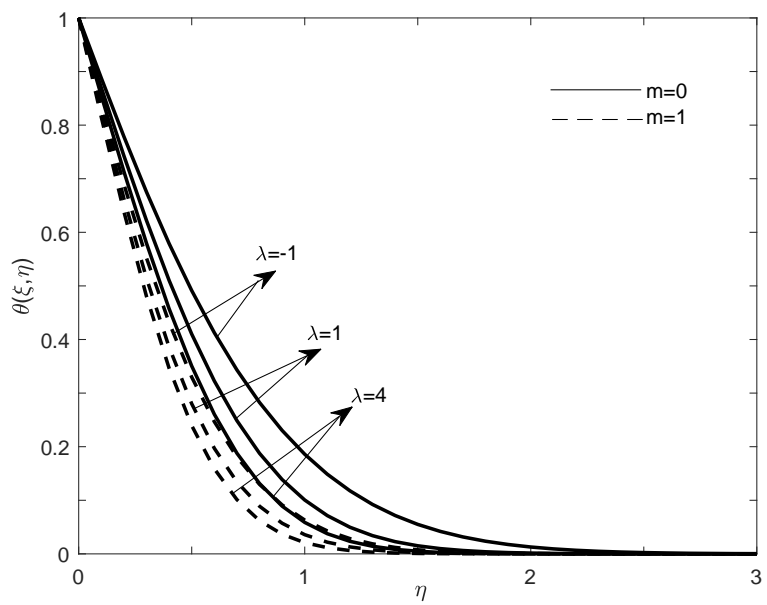

Fig. 3 Effects of $\lambda$ and $m$ on temperature profile for $\epsilon=0.2$ and $\xi=1.0$

exponent parameters $(\lambda$ and $m$ ) have less effect on the $\theta$ as compare to the $F$. For example, for $\epsilon=0.2, \xi=1.0$ and $\eta=1$ the magnitude of $\theta$ decreases about $64 \%$ by a unit increment in $m$ from 0 for $\lambda=1$.

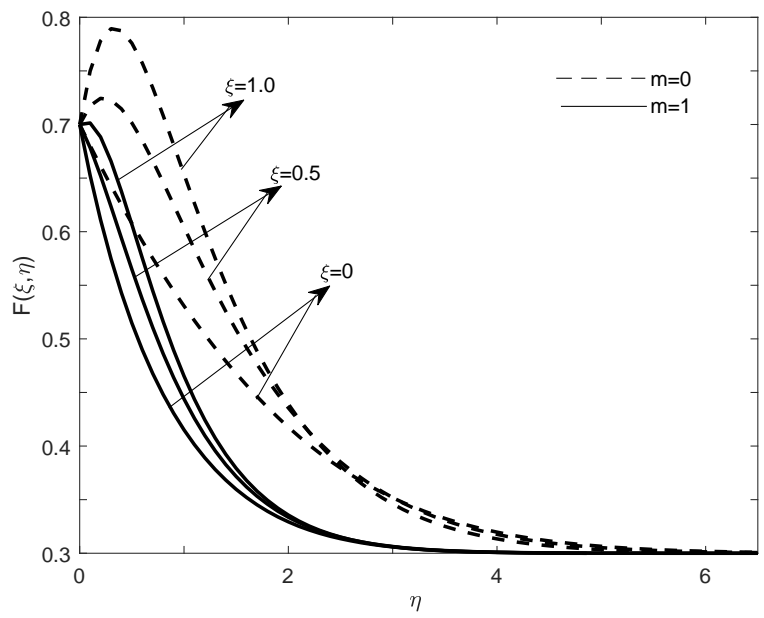

Fig. 4 Effects of $\xi$ and $m$ on velocity profile for $\epsilon=0.3$ and $\lambda=2$

The impact of exponent parameter $(m)$ and streamwise coordinate $(\xi)$ on the velocity profile $(F)$ are displayed in Fig 4 . The overshoot in velocity profile is noted for $\xi=0.5$ and $\xi=1$ at $m=0$ whereas the overshoot is absent for linear stretching sheet $m=1$, irrespective of $\xi$. For example, as $\mathrm{m}$ increases from 0 to $1, \xi=1$ the velocity profile decreases approximately by $35 \%$ at $\eta=1, \epsilon=0.2$ and $\lambda=-1$. The physical reason is that streamwise coordinate $\xi$ act as a favorable pressure gradient within boundary layer and hence fluid moves faster. Also, for $\mathrm{m}=0$, the magnitude of velocity profile increases by $15 \%$ as $\xi$ increases from 0 to 0.5 , $\lambda=2, \eta=0.5$ at $\epsilon=0.3$. Figure 5 explains the effect of streamwise coordinate and exponent parameter on the temperature profile. Similar to Figure 3, The temperature gradient reduces at the surface because higher value of $\xi$ and $m$ has high thermal conductivity, causing the fluid to attain higher temperature thereby reducing the heat flux at the surface. For example, for $\lambda=2, \xi=1$ and $\epsilon=0.3$ the temperature $(\theta)$ decreases $63 \%$ by increment in $m$ from 0 to 1 at $\eta=1$. Figure 6 variation of velocity profile for various value of $\epsilon$ and $m$. It is noted that the $F$ decreases with increase of $m$ but overshoot are increased with increase of $\epsilon$. The reason is high assisting buoyancy force acting on favourable pressure gradient due to the thermal radiation which is enhance the fluid flow uniform motion $(m=0)$ cause the velocity overshoot is moving over a near the 


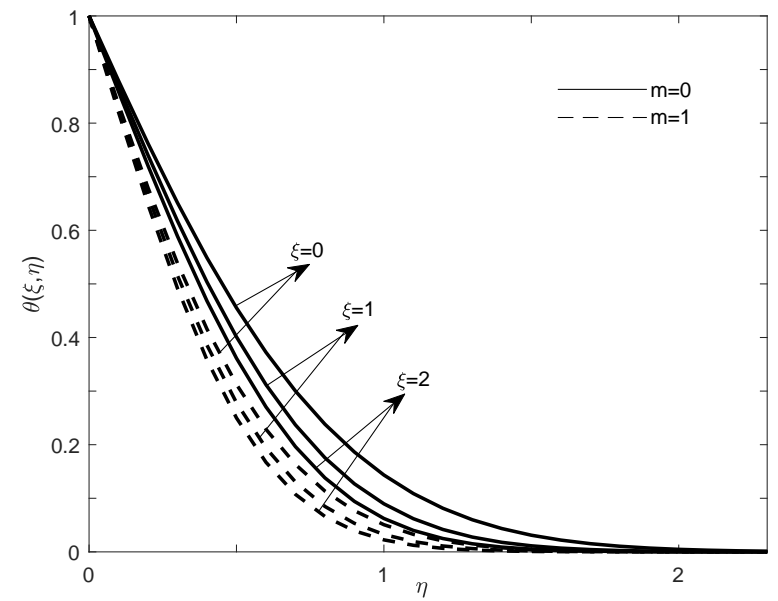

Fig. 5 Effects of $\xi$ and $m$ on temperature profile for $\epsilon=0.3$ and $\lambda=2$

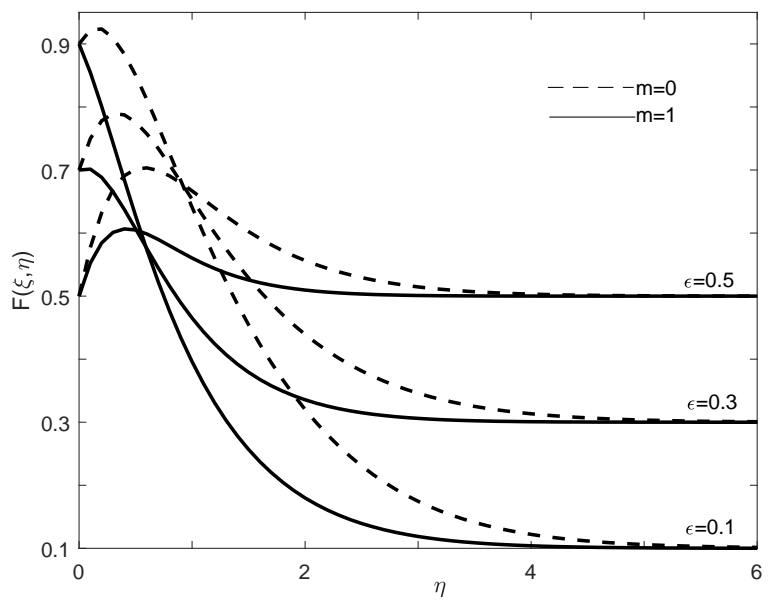

Fig. 6 Effects of $\epsilon$ and $\mathrm{m}$ on velocity profile for $\xi=1.0$ and $\lambda=2$

surface. But the velocity overshoot is absent for uniform stretching sheet $(m=1)$. For example, when $m=0, \epsilon=0.5$ and $\lambda=2$, maximum velocity overshoot is observed as $40 \%$ at $\eta=0.6$ for $\xi=1.0$. Also, for $\epsilon=0.5, \xi=1.0$ and $\lambda=2$, the magnitude of velocity profile increases close to $19 \%$ by varying $m$ from 1 to 0 at $\eta=1$. The effects of the

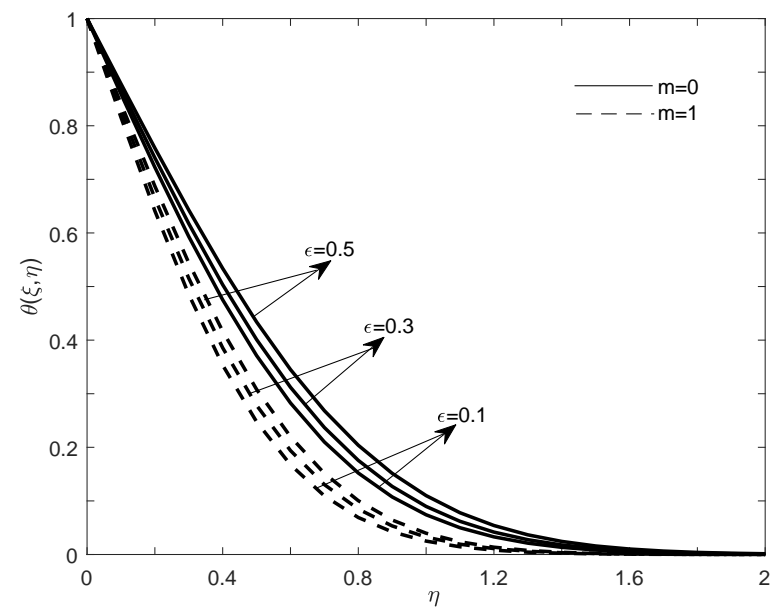

Fig. 7 Effects of $\epsilon$ and $\mathrm{m}$ on temperature profile for $\lambda=2$ and $\xi=1.0$ temperature profile $(\theta)$ for different values of $\epsilon$ and $m$ are presented in Figure 7. Similar to Figures 3 and 5, temperature profile shows decreasing trend with $\eta$ and hence similar explanation follows. However, as $\epsilon$ increases, the magnitude of $\theta$ increases. The thermal thickness is much smaller for linear stretching sheet $m=1$ compare to the lower range of uniform motion $m=0$. In particular, for $m=1, \lambda=2$ and $\xi=1$ and temperature increases by $24 \%$ as $\epsilon$ increases from $\epsilon=0.1$ to $\epsilon=0.5$ at $\eta=0.5$. Figure 8 shows that influences of $\lambda$ and $m$ on the skin friction

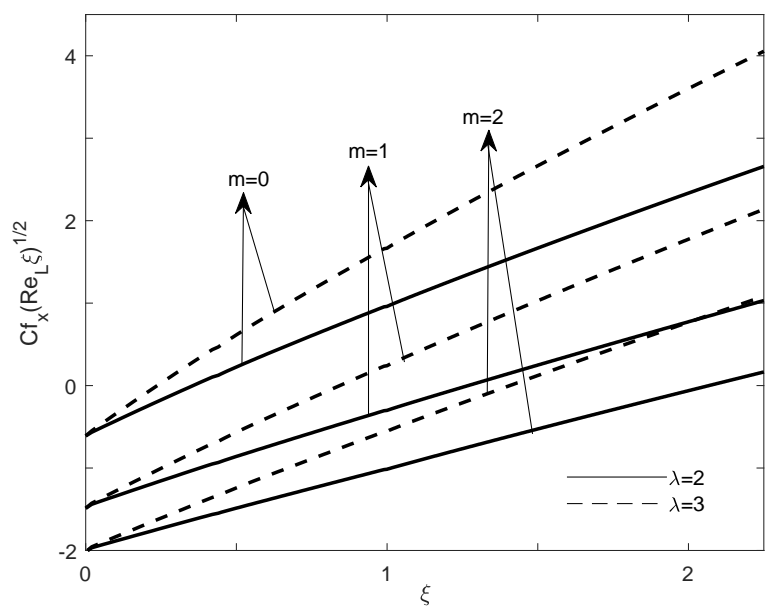

Fig. 8 Effects of $\lambda$ and $\mathrm{m}$ on skin friction coefficient for $\epsilon=0.2$

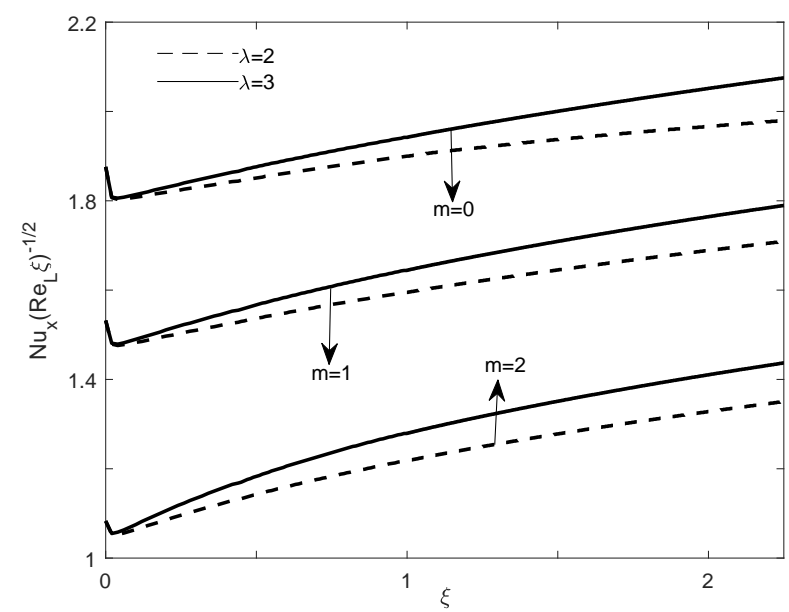

Fig. 9 Effects of $\lambda$ and $\mathrm{m}$ on heat transfer rate for $\epsilon=0.5$

$\left(C_{f x}\left(R e_{L} \xi\right)^{1 / 2}\right)$. The skin friction coefficient increases with $\lambda$ leads to a decrease with an increase of $m$. The power-law stretching sheet reduces the velocity gradient on the surface. The velocity gradient of the surface $C_{f x}\left(\operatorname{Re}_{x} \xi\right)^{1 / 2}<0$ implies that the fluid is being dragged by the plate and $C_{f x}\left(R e_{x} \xi\right)^{1 / 2}>0$ implies that the plate is being dragged by the fluid. In particular, the skin friction coefficient $\left(C_{f x}\left(R e_{L} \xi\right)^{1 / 2}\right)$ increases about $59 \%$ as $\lambda$ increases from 2 to 3 at $\xi=1.5, m=0$ and $\epsilon=0.2$. Figure 9 presented the variations of heat transfer coefficients $\left(N u_{x}\left(R e_{L} \xi\right)^{-1 / 2}\right)$, w hen $\lambda$ and $m$. Heat t ransfer coefficient $\left(N u_{x}\left(R e_{L} \xi\right)^{-1 / 2}\right)$ increases with increase of $\lambda$ and $\mathrm{m}$. For example, the heat transfer increases close to $4 \%$ by impact of increment in $\lambda$ by 2 to 3 at $\xi=0.5, \epsilon=0.5$ and $m=0$. 


\section{CONCLUSIONS}

The current problem is carried out the numerical investigation of fluid flow above stretching sheet with variable viscous fluid and Prandtl number. The numerical results are graphically represented for various parameter values of boundary layer flow. The main findings are summarized below:

- The effects of streamwise coordinate $(\xi)$ and m. For example, as $\xi$ increases from $\xi=0$ to $1, \eta=1$ and $\lambda=2$ the magnitude of velocity increases approximately by $13 \%$ at $=0.3$.

- The buoyancy force $(\lambda)$ induced the overshoot in the velocity profile.For example, when $=0.3, \lambda=2$ and $m=0$, the velocity profile overshoot increases by $13 \%$ as $\eta$ increases from $\eta=0$ to 0.4 at $\xi=1$.

- Increasing trend in the skin friction coefficient $\left(C_{f x}\left(\operatorname{Re}_{L} \xi\right)^{1 / 2}\right)$ is observed for increase of the buoyancy parameter and its increases approximately by $48 \%$ as $\lambda$ increases from $\lambda=2$ to 3 at $m=2, \xi=$ $0.5,=0.2$ respectively.

- The magnitude of heat transfer $\left(N u x(\operatorname{Re} L \xi)^{-1 / 2}\right)$ increases with $\lambda$ as it increases approximately by $3 \%$ as $\lambda$ increases from 2 to 3 at $=0.2, \xi=1.5$ and $m=2$.

- The effects of the velocity ratio $(\epsilon)$ and $\mathrm{m}$. For example, as increases from $=0.1$ to $\lambda=2, \mathrm{~m}=1$ the velocity profile increases approximately by $31 \%$ at $\eta=1.0, \epsilon=0.5$, and $\xi=1$.

\section{NOMENCLATURE}

$C_{w}$

$C f_{x}$

$C_{\infty}$

C
f
$F$

F

G

$m$

$N$

$N u_{x}$

$\operatorname{Pr}$

$R e_{L}$

$T_{\infty}$

$T_{w}$

\section{$U$}

$u$

$U_{\infty}$

$U_{w}$

$v$

Greek symbols

$\begin{array}{ll}\rho & \text { Density }\left(\mathrm{kgm}^{-3}\right) \\ \psi & \text { Streamfunction }\end{array}$

Streamfunction

$v \quad$ Kinematic viscosity $\left(\mathrm{m}^{2} \mathrm{~s}^{-1}\right)$

$\lambda \quad$ Mixed convection parameter

$\mu \quad$ Viscosity $\left(\mathrm{kgm}^{-1} \mathrm{~s}^{-1}\right)$

Ratio between free stream

velocity and the reference velocity

\section{REFERENCES}

Rezaeianjouybari, B., Sheikholeslami, M., Shafee, A., and Houman Babazadeh., 2020, "A novel Bayesian optimization for flow condensation enhancement using nanorefrigerant: A combined analytical and experimental study," Chemical Engineering Science, 215(6), 115465.

https://doi.org/10.1016/j.ces.2019.115465

Sravanthi, C.S., 2019,"Effect of nonlinear thermal radiation on silver and copper water nanofluid flow due to a rotating disk with variable thickness in the presence of nonuniform heat source and sink using the homotopy analysis method," Heat transfer asian research, 48(8), 1-16. https://doi.org/10.1002/htj.21581

Sravanthi, C.S., 2019, "Effect of heat source and sink on MHD flow due to porous rotating disk with variable thickness in the presence of cross diffusion," Heat transfer asian research, 48(8) 1-17. https://doi.org/10.1002/htj.21580

Sravanthi, C.S., 2019, "Second order velocity slip and thermal jump of $\mathrm{Cu}$-waternanofluid overaconein the presence of nonlinear radiation and nonuniform heat source and sink using homotopy analysis method," Heat transfer asian research, 49, 86-102.

https://doi.org/10.1002/htj.21600

Sravanthi, C.S., 2018, "Slip flow of nanofluid over a stretching vertical cylinde- in the presence of non-linear thermal radiation and non-uniform heat source/sink," Scientia Iranica B, 25(4), 2098-2110. https://doi.org/10.24200/sci.2017.4580

Sravanthi, C.S., and Gorla,R.S.R., 2018, "Effects of heat source/sink and chemical reaction on MHD maxwell nanofluid flow over a convectively heated exponentially stretching sheet using homotopy analysis method," Int. J. App. Mech. Engg, 23(1), 137-159. https://doi.org/10.1515/ijame-2018-0009

Sravanthi, C.S., and Gorla,R.S.R., 2018, "Radiation absorption and chem- ical reaction effects on rivlin ericksen flow past a vertical moving porous plate,” Int. J. App. Mech. Engg, 24(3), 675-689. https://doi.org/10.2478/ijame-2019-0042

Chen, C.H., 2000, "Mixed convection cooling of a heated, continuously stretching surface," Heat Mass Transfer, 36, 79-86.

https://doi.org/10.1007/s002310050367

Raju, C.S.K., Sandeep, N., Sugunamma, V., Babu, M.J., and Reddy, J.V.R., 2016, "Heat and mass transfer in magnetohydrodynamic casson fluid over an exponentially permeable stretching surface,"

Engg. Sci. Tech. Inter. Journal, 19(1), 45-52.

https://doi.org/10.1016/j.jestch.2015.05.010

Chen, C.H., 1998, "Laminar mixed convection adjacent to vertical, con- tinuously stretching sheets," Heat and Mass transfer, 33, 471476 .

Lide,D.R.(Ed.)., 1990, "CRC Handbook of Chemistry and Physics," 71st ed., CRC Press, BocaRaton, FL.

Mureithi, E.M., Mwaonanji, J.J., and Makinde, O.D.,2013, "On boundary layer flow over a moving surface in a fluid with temperature-dependent viscosity," O. J. Fluid Dynamics, 3(2), 135140.

https://doi.org/10.4236/ojfd.2013.32017

Elbashbeshy, E.M.A.,2001, "Heat transfer over an exponentially stretch- ing continuous surface with suction," Arch. Mech, 53(6), 643651 .

Tsou, F.K., Sparrow, E.M., and Goldstein, R.J., 1967, "Flow and heat 
transfer in the boundary layer on a continuous moving surface," Int. J. Heat and Mass Transfer, 10(2), 219-235. https://doi.org/10.1016/0017-9310(67)90100-7

Mabood, F., and Shateyi,S., 2019, "Multiple Slip Effects on MHD Unsteady Flow Heat and Mass Transfer Impinging on Permeable Stretching Sheet with Radiation," Modelling and Simulation in Engg, 11 pages, Article ID 3052790.

https://doi.org/10.1155/2019/3052790

Revathi, G., Saikrishnan, P., and Ali Chamkha., 2014, "Non-similar solutions for unsteady flow over a yawed cylinder with non-uniform mass transfer through a slot,” A. S. Engineering Journal, 5(4), 1199-1206. https://doi.org/10.1016/j.asej.2014.04.009

Schlichting, H., 2000, "Boundary Layer Theory," New York, McGraw Hill.

Roy, S., and Saikrishnan, P., 2003, "Non-uniform slot injection (suction) into steady laminar boundary layer flow over a rotating sphere," Int. J. Heat and Mass Transfer, 46(18), 3389-3396.

https://doi.org/10.1016/S0017-9310(03)00137-6

Pop, I., Gorla, R.S.R., and Rashidi, M., 1992, "The effect of variable viscosity on flow and heat transfer to a continuous moving flat plate," Int. J. Engg. Science, 30(1), 1-6.

https://doi.org/10.1016/0020-7225(92)90115-W

Umavathi, J.C., Chamkha, A.J., and Mohiuddin, S., 2016, "Combined Effect of variable viscosity and thermal conductivity on free convection flow of a Viscous Fluid in a Vertical Chennal," Int. J. Num. methods Heat and Fluid Flow, 26(1), 18-39.

Crane, L.J.,1970, "Flow past a stretching plate," Mathematics, J.A., and Physics, 21, 645-647.

Krishnaa, M.V., Sravanthib, C.S., and Gorlac, R.S.R., 2020, "Hall and ion slip effects on MHD rotating flow of ciliary propulsion of micro- scopic organism through porous media," Int. Commu. Heat and Mass Transfer, 112, 104500. https://doi.org/10.1016/j.icheatmasstransfer.2020.104500

Sheikholeslami, M., Jafaryar, M., Shafee, A., and Babazadeh, H., 2020, "Acceleration of discharge process of clean energy storage unit with insertion of porous foam considering nanoparticle enhanced paraffin, Journal of Cleaner Production," 261, 121206.

https://doi.org/10.1016/j.jclepro.2020.121206

Sheikholeslami, M., 2019, "New computational approach for exergy and entropy analysis of nanofluid under the impact of Lorentz force through a porous media," Comput. Methods Appl. Mech. engineering, 344, 319333.

https://doi.org/10.1016/j.cma.2018.09.044

Sheikholeslami, M., Rezaeianjouybari, B., Milad Darzi., Ahmad Shafee., Zhixiong Li., and Truong Khang Nguyen., 2019, “Application of nanorefrigerant for boiling heat transfer enhancement employing an experimental study," Int. J. Heat and Mass Transfer, 141, 974-980.

https://doi.org/10.1016/j.ijheatmasstransfer.2019.07.043

Jashim Uddin, M., Khan, W.A., Izani, A., and Ismail, M., 2015, "Similarity solution of double diffusive free convection flow over a moving vertical flat plate with convective boundary condition," Ain Shams Engg. Journal, 6(3), 1105-1112. https://doi.org/10.1016/j.asej.2015.01.008

Afzal, N., 2003, "Momentum transfer on power law stretching plate with free stream pressure gradient,” Int. J. Engg. science, 14(11), 1197-1207. https://doi.org/10.1016/S0020-7225(03)00002-8

Nadeem., Rizwan UL Haq., and Zafar Hayat Khan., 2014, "Heat transfer analysis of water-based nanofluid over an exponentially stretching," A. E. journal, 53(1), 219-224.

https://doi.org/10.1016/j.aej.2013.11.003

Ismail, N.S., Arifin, N.Md., Bachok, N., and Mahiddin, N.,2016, "Flow and heat transfer on a moving flat plate in a parallel stream with constant surface heat flux:A stability analysis," I. J. Science and Technology, 9(31), 0974-6846.

https://doi.org/10.17485/ijst/2016/v9i31/97732

Alreshidi, N.A., Shah, Z., Dawar, A., Kumam, P., Shutaywi, M., and Watthayu, W., 2020, "Brownian Motion and Thermophoresis Effects on MHD Three Dimensional Nanofluid Flow with Slip Conditions and Joule Dissipation Due to Porous Rotating Disk," Molecules , 25(3), 729.

https://doi.org/10.3390/molecules25030729

Govindaraj, N., Singh, A.K., Roy, S., and Shukla, P.,2019, “Analysis of a boundary layer flow over moving an exponentially stretching surface with variable viscosity and Prandtl number," Heat transfer, 48(7), 2736-2751. https://doi.org/10.1002/htj.21508

Makinde, O.D., Khan, W.A., and Khan, Z.H.,2013, "Buoyancy effects on MHD stagnation point flow and heat transfer of a nanofluid past a convectively heated stretching/shrinking sheet," Int. J. Heat and Mass Transfer, 62, 526-533.

https://doi.org/10.1016/j.ijheatmasstransfer.2013.03.049

Patil, P.M., Roy, S., and Chemkha, A.J., 2010 "Mixed convection flow over a vertical power law stretching sheet," Int. J. N. Methods Heat Fluid Flow, 20(4), 445-458.

https://doi.org/10.1108/09615531011035839

Dulal, P., 2017, "Mixed convection heat transfer in the boundary layers on an exponentially stretching surface with magnetic field," Applied Mathematics and Computation, 217(6), 2356-2369.

https://doi.org/10.1016/j.amc.2010.07.035

Singh, P.J., and Roy, S., 2008, "Unsteady mixed convection from a rotating vertical slender cylinder in an axial flow," Int. J. Heat and Mass Transfer, 51(5), 1423-1430.

https://doi.org/10.1016/j.ijheatmasstransfer.2007.11.024

Kandasamy, R., Dharmalingam, R., and Prabhu, K.K.S., 2018 "Thermal and solutal stratification on MHD nanofluid flow over a porous vertical plate," Alexa. Eng. Journal, 57(1), 121-130.

https://doi.org/10.1016/j.aej.2016.02.029

Varga, R.S., 2000, “Matrix Itrative Analysis,” Prentice Hall, Englewood Cliffs,NJ.

Nadeem, S., Haq, R.U., Akbar,N., and Khan, Z.H., 2014, "MHD threedimensional casson fluid flow past a porous linearly stretching sheet," A. E. journal, 52(4), 577-582.

https://doi.org/10.1016/j.aej.2013.08.005

Islam, S., Kumam, P., and Thounthong, P., 2020, "Micropolar Gold Blood Nanofluid flow and Radiative Heat Transfer between Permeable Channels," Cmoput. Meth. Prog. Bio, 186, 105197.

https://doi.org/10.1016/j.cmpb.2019.105197

Hayat, T., Shehzad, S.A., and Alsaedi, A., 2014, "MHD Three-Dimensional 
Flow by an Exponentially Stretching Surface with Convective Boundary Condition," J. A. Engineering, 27(4).

Soundalgekar, V.M., and Murty, T.V.R., 1980, "Heat transfer in flow past a continuous moving plate with variable temperature," Warme-und Stof- fubertragung, 14, 91-93.

Ibseini, Y., and Makinde, O.D., 2013, "MHD boundary layer flow due to exponential stretching surface with radiation and chemical reaction," Hindawi Mathematical Problems in Engineering, 7 pages, Article ID 163614. https://doi.org/10.1155/2013/163614 